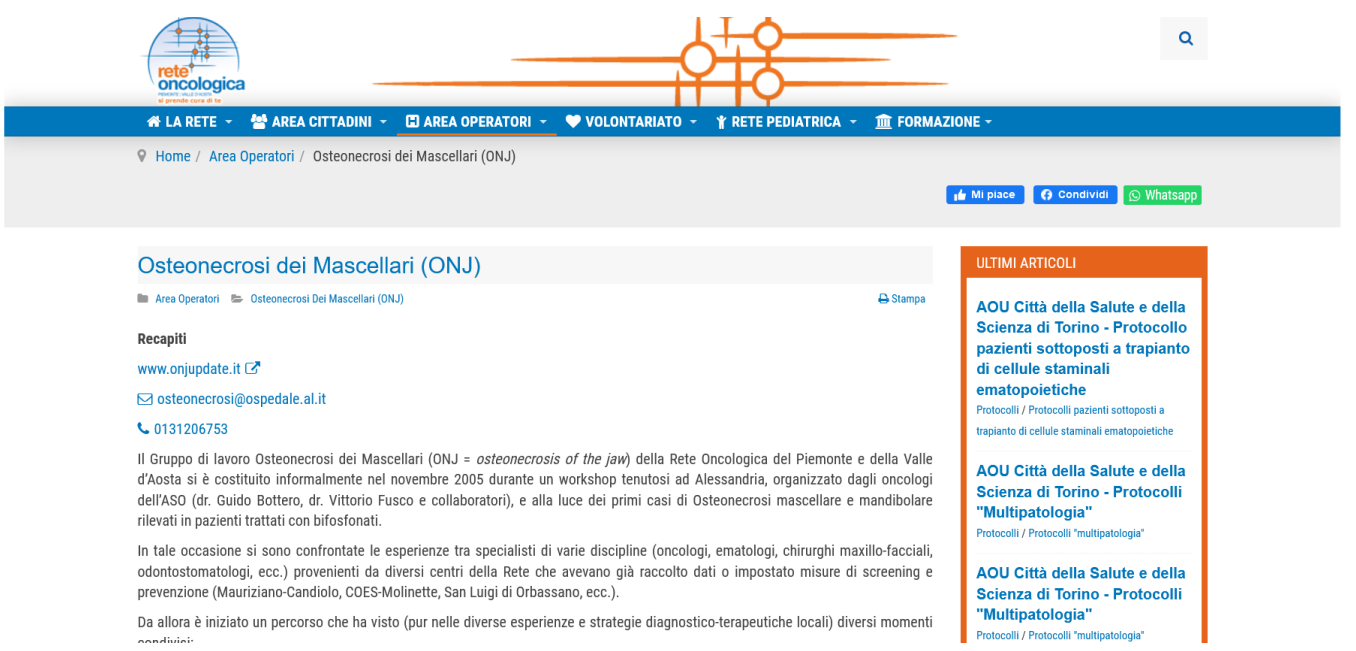

\title{
A web site page for information about Osteonecrosis of Jaw (ONJ): the Rete Oncologica Piemonte e Valle d'Aosta experience, at www.reteoncologica.it
}

\author{
Vittorio Fusco ${ }^{1}$, Angelica Carobene ${ }^{2}$, marinella mistrangelo ${ }^{2}$, GIANFRANCO FERRERO $^{3}$, Gianmauro Numico ${ }^{4}$ \\ 1 Azienda Ospedaliera SS. Antonio e Biagio e Cesare Arrigo \\ 2 A.O.U. Citta della Salute e della Scienza di Torino \\ 3 Rete Oncologica del Piemonte e della Valle d'Aosta \\ 4 Azienda Sanitaria Ospedaliera S.Croce e Carle Cuneo
}

Funding: The author(s) received no specific funding for this work.

Potential competing interests: The author(s) declared that no potential competing interests exist.

\section{Abstract}

Osteonecrosis of the Jaw (ONJ) related to drugs (bisphosphonates, denosumab, antiangiogenic and other agents) is an issue of care by the "Rete Oncologica di Piemonte e Valle d'Aosta" since 2005. The "Rete Oncologica" is a cancer network that include professionals (physicians, nurses, technicians, supporting staff, data managers, etc) of all the healthcare units that manage and treat patients with cancer and hematologic disorders in two regions (Piedmont and Aosta Valley, globally 4.4 million population) in the North-Western Italy. Besides study groups, research grants and organization of meetings, in order to facilitate the awareness of ONJ issues, on 2014 the network created specific ONJdedicated pages on the network website www.reteoncologica.it . In the area for healthcare staff, the reader can find an ONJ title, that opens to a ONJ front page (http://www.reteoncologica.it/area-operatori/osteonecrosi-dei-mascellari-onj) presenting links to recent issues (recommendations, meetings, papers, etc) and to an Archive with previous contents, classified for year (http://www.reteoncologica.it/area-operatori/osteonecrosi-dei-mascellari-onj/185-documenti-e-slide) . Preliminary altmetric evaluation of the ONJ pages (number of visits; median time of stay; etc) show a variable but 
steady access to the ONJ contents of the website, with occasional peaks.

Background: Osteonecrosis of the Jaw (ONJ) is an uncommon (not rare) disease recognized since 2003 as associated to treatment with some drugs (increasing in number and classes). ONJ is more frequently observed in bone metastatic cancer and myeloma patients receiving antiresorptive treatments (bisphosphonates and denosumab) with/without biological agents, but it is also diagnosed in patients receiving bisphosphonates and denosumab for osteoporosis and other non malignant bone disorders. Awareness of ONJ increased since 2005 but it is still insufficient, as well as knowledge about risk assessment, predictive factors, management and treatment strategies. Since 2004 alert about ONJ started among some oncologists, hematologists, oral care specialists also in Piedmont and Aosta Valley (globally 4.4 million population) in the Norht-Western Italy, after observation of apparently first ONJ cases in cancer and myeloma patients.

The "Rete Oncologica di Piemonte e Valle d'Aosta" is a cancer network that include professionals (physicians, nurses, technicians, supporting staff, data managers, etc) of all the healthcare units that manage and treat patients with cancer and haematologic disorders in those two regions. On November 2005 the network organized a meeting among several figures involved in ONJ diagnosis, management, and treatment. A multiprofessional ONJ Study Group started cases collection (still ongoing: more than 800 cases collected at the end of 2020)[1][2][3][4] , meetings (at regional and national level) and guideline diffusion.

On 2014, as ONJ became a relevant issue of activity of the network, the Rete Oncologica head office created a ONJdedicated space on the well-followed network website www.reteoncologica.it .

The introductive page for professional area http://www.reteoncologica.it/area-operatori includes a link, that opens to a specific ONJ page: http://www.reteoncologica.it/area-operatori/osteonecrosi-dei-mascellari-onj . The forntline ONJ page links to recent issues (recommendations, meetings, papers, etc) of interest and to an "Archive" with previous contents, classified for year (http://www.reteoncologica.it/area-operatori/osteonecrosi-dei-mascellari-onj/185-documenti-e-slide), including acta and slides of all the ONJ meetings. The website pages are visited not only by network professionals, but also by other Italian professionals, that are largely involved on ONJ study and research[5][6].

Materials and Methods: Data about visits at the ONJ pages have been collected by usual web tools. Web traffic was defined in terms of page views and visits, for time period. Other details (including time duration per visit) are illustrated in figure 1 and 2 . 
- Visualizzazioni di pagin
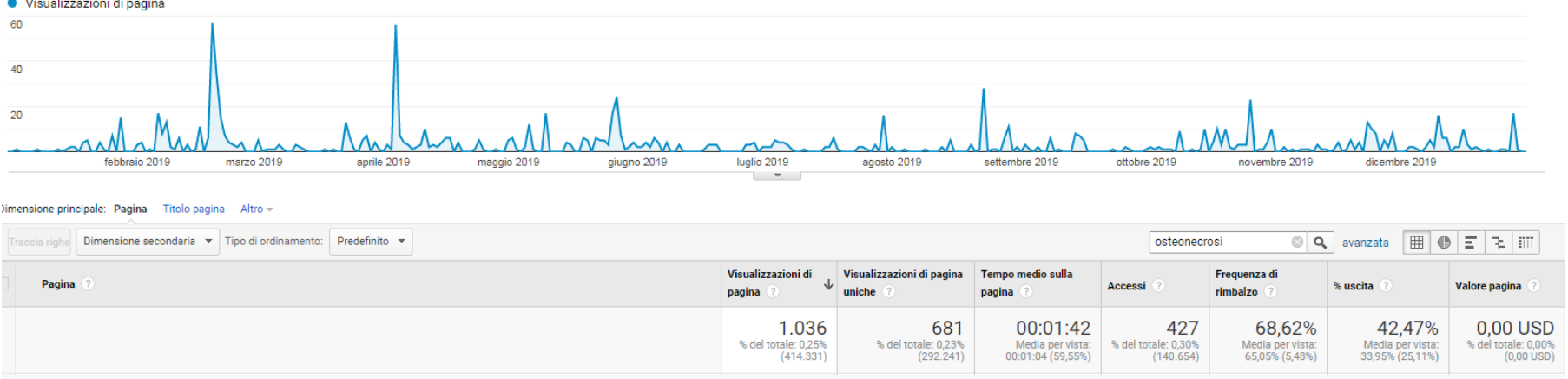

Figure 1 - Visits in 2019 year
Tutti gli utenti
+ Aggiungi segmento

Esplorazione Riepilogo navigazione

Visualizzazioni di pagina - e Seleziona una metrica

- Visualizzazioni di pagina

20
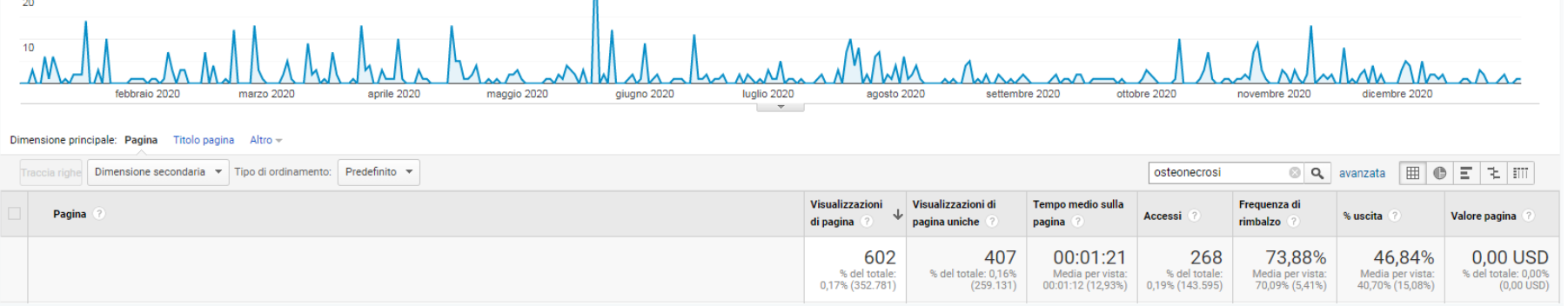

Figure 2 - Visits in 2020 year

Preliminary Results: The visits decreased in 2020 year (in comparison with 2019) but increased in the first months of 2021.

The study is ongoing, in order to analyze frequency and peaks of visits, time duration per visit, more visited single pages and other data.

Some peaks of visits seem to be present in occasion of publication on the website homepage of papers, guidelines, meeting announcement (see example in figure 3). 


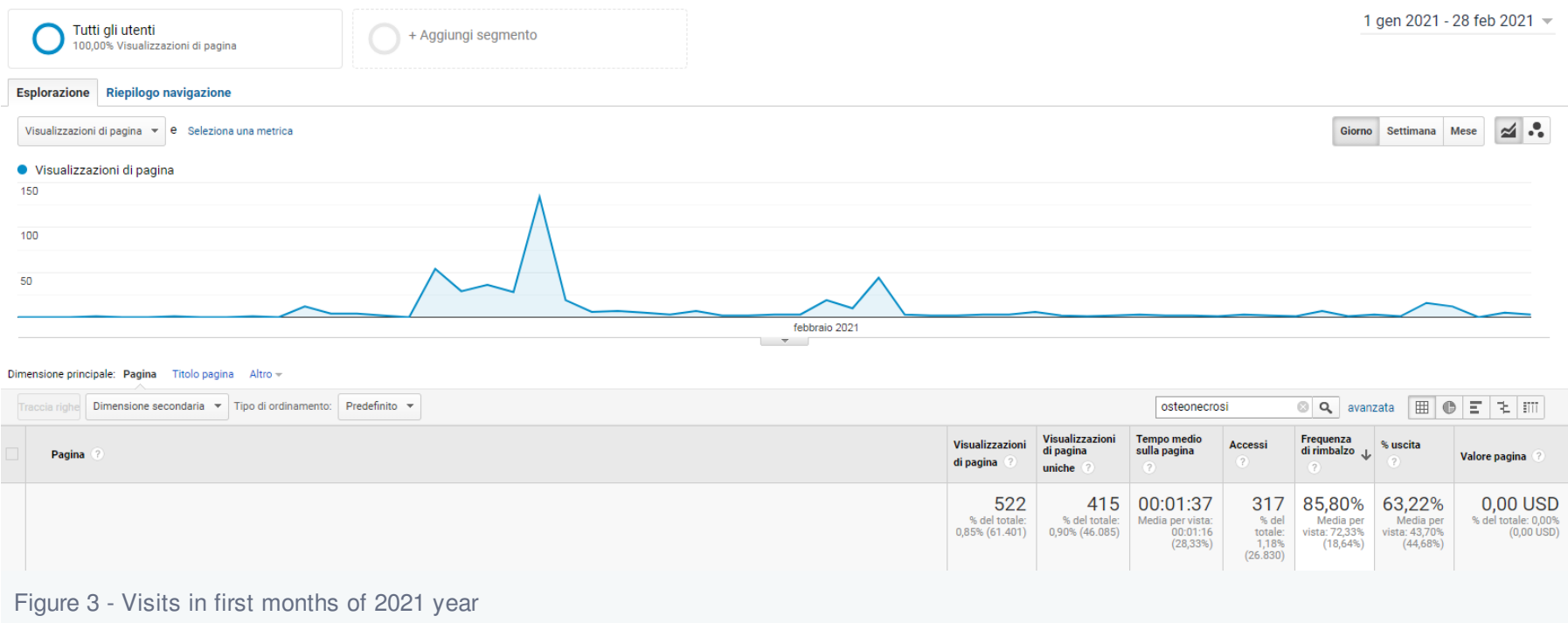

Conclusions. The ONJ-dedicated pages of the website www.reteoncologica.it are visited by professionals of the network in a variable manner, with some occasional peaks. Tools aimed to increase the visit frequency are to be planned .

\section{References}

1. 'Vittorio Fusco, Claudia Galassi, Alfredo Berruti, Cinzia Ortega, et al. (2013). Decreasing Frequency of Osteonecrosis of the Jaw in Cancer and Myeloma Patients Treated with Bisphosphonates: The Experience of the Oncology Network of Piedmont and Aosta Valley (North-Western Italy). ISRN Oncology, vol. 2013 , 1-8. doi:10.1155/2013/672027.

2. 'V. Fusco, M. Cabras, F. Erovigni, A. Dell'Acqua, et al. (2020). A multicenter observational study on MedicationRelated Osteonecrosis of the Jaw (MRONJ) in advanced cancer and myeloma patients of a cancer network in NorthWestern Italy. Med Oral. doi:10.4317/medoral.24318.

3. 'MARCO CABRAS, Alessio Gambino, Francesco Maria Erovigni, FRANCESCO DELLA FERRERA, et al. (2021). OSTEONECROSIS OF THE JAW (ONJ) IN CANCER AND MYELOMA PATIENTS. A 16-YEAR EXPERIENCE OF “RETE ONCOLOGICA PIEMONTE-VALLE D'AOSTA"CANCER NETWORK. Qeios. doi:10.32388/YIVAW8.

4. `Alessio Gambino, MARCO CABRAS, Francesco Maria Erovigni, Alessandro Dell'Acqua, et al. (2021).

$$
\text { OSTEONECROSIS OF JAW (ONJ) IN PATIENTS WITH OSTEOPOROSIS AND OTHER NON-MALIGNANT }
$$
DISEASES IN PIEDMONT AND AOSTA VALLEY 2004-2018. Qeios. doi:10.32388/RFSJ8T.

5. ' V. Fusco, A. Baraldi, A. Fasciolo, M. Rapetti, et al. (2012). Osteonecrosis of jaw (onj): impact of italian patients, and role of italian physicians, dentists, and researchers in the growing evidence of a "new" disease. Work Paper Public HIth, vol. 1 (1). doi:10.4081/wpph.2012.6778.

6. 'M. Rapetti, I. De Martino, L. Randi, P. Pepe, and V. Fusco. (2014). Osteonecrosis of jaw (ONJ) in Italy: 2014 update of role of Italian patients, physicians, dentists, researchers. Ann Stomatol (Roma). 2014 Apr-Jun; 5(2 Suppl): $34 .$. 